\title{
AHP IN EHEALTH: THE MISSING PUZZLE BETWEEN (USERS') NEEDS ELICIATION, REQUIREMENTS DESIGN AND SPECIFICATION WRITING.
}

\begin{abstract}
The AHP has been used in healthcare technology in several manners, ranging from user needs elicitation to decision making for health technology assessments and budget prioritization. The eHealth paradigm, defined as catalyst for innovation in healthcare, can benefit from the AHP to systematically link user needs, user requirements and specifications reporting, when defining eHealth-based solution. This papers inform on the experience derived from the application of AHP in 3 cases.
\end{abstract}

Keywords: AHP, eHealth, holistic roadmaps, multidisciplinary requirements.

\section{Introduction}

The need to define new concepts, domains and research areas, to keep up with the pace of the evolution of technological innovations in healthcare is continuous. The rise of Internet and the possibility to integrate different services in different environments like homes, hospitals, pharmacies, but also laboratories, wellness centres etc. generated a vision where all these environments are connected through ICT, share data and collaborate to provide better health care. That is way, since the early 2000 , more than concepts and research areas, the need to create paradigms, visions and umbrella terms has been evident. That is what happened, for instance, when the eHealth concept has started to appear.

The European Federation of Medical Informatics presented, in the report eHealth in Europe - Status and Challenges, that support is needed to "shift from a strict ICT focus on ICT implementation to a comprehensive, holistic approach acknowledging that eHealth involves interplay of appropriate technical and social infrastructure, secure repositories and usable applications". It is not by chance that in same period, the need for holistic evidencebased frameworks to design eHealth solutions that aim at bring positive and sustainable impact for a given healthcare problem have appeared. In the work A Holistic Framework to Improve the Uptake and Impact of eHealth Technologies, van Gemert-Pihnen et al., made a literature search to identify potential and limitations of eHealth frameworks from 1999 to 2009. They found that a not clear relationship between eHealth visions, proposed strategies and research methods emerged, due to a conceptual approach focused on the rationale behind the frameworks, rather than focused on practical guidelines and on a more stakeholders-driven approach. They finally proposed a new holistic framework, the CEHRES Roadmap, to overcome these barriers, built on a participatory development approach, persuasive design techniques and business modelling, serving as an evidencebased roadmap. The roadmap consists of five phases (contextual inquiry, value specifications, design, operationalization and summative evaluation). Throughout the development process, formative evaluations are conducted in order to test design assumptions and prototypes. It is in the first phases qhen the roadmap prvide guidance in termes of tasks methods o. How to define the healthcare problem that one want to solve and, in a structured, iterative and hierarchical procedures identify and formally define three derivatives: Values, Attributes and Requirements. A Value "is an ideal or interest aend user or stakeholder aspires to or has"; an Attribute is "a summary of the need or wish that is 
spoken out by the (future) end user or stakeholder"; a Requirement is "a technical translation of an attribute". This way, this roadmap provide a guidance on how structure a healthcare problem. The connection with methods like the Analytic Hierarchy Process is evident and in fact the authors suggest this method to structure the Healthcare problem, while a multidisciplinary requirement development approach is suggested to determine the other derivatives,. In this method, for each part of a transcript that is worthy of translation into a requirement, the three derivatives are determined.

\section{Hypotheses/Objectives}

We have used the AHP to support the definition of multidisciplinary requirements, as not always is possible to start with a good set of transcript due to time and resources constraints.

\section{Research Design/Methodology}

To structure a Healthcare problem through the AHP and determine the main components in three (H. Problem, Values, Attribute) or four level (Healthcare Problem, Values, Attribute, Specifications), depending on the complexity and on the needs of the project, upon consultation with an AHP expert.

\section{Limitations and Conclusions}

The method has been successfully used to design eHealth interventions for older adults, to design tools for diabetes risk stratifications and for technology-oriented, family-based interventions in Childhood Obesity. The AHP was selected for pragmatic reasons, to solve in a quick and efficient manner the management of multidisciplinary research projects of the eHealth domain. Therefore, the message provided aims at stimulating a debate and reflections and eventually perform a systematic approach to discover, verify and properly assess all the results. If the advantage of using a holistic approach resides in the fact that the result is more than the sum, the usage of derive hierarchies, priorities and categories allow organizing R\&D activities in working groups and at the same time to justify domain interactions, as well as to prioritize and plan them.

\section{Key References}

- Saaty TL. Decision making with the analytic hierarchy process. Int. J. Services Sciences 2008;1;1;83-98.

- Pecchia, L., Bath, P. A., Pendleton, N., \& Bracale, M. (2010). Web-based system for assessing risk factors for falls in community-dwelling elderly people using the analytic hierarchy process. Internationa Journal of the Analytic Hierarchy Process, 2(2).

- Fico, G., Gaeta, E., Arredondo, M. T., \& Pecchia, L. (2015). Analytic hierarchy process to define the most important factors and related technologies for empowering elderly people in taking an active role in their health. Journal of medical systems, 39(9), 1-7.

- Hu, R., Cancela, J., Waldmeyer, M., Cea, G., Vlachopapadopoulou, E., Fotiadis, D., \& Fico, G (2016). OB CITY-Definition of a Family-Based Intervention for Childhood Obesity Supported by Information and Communication Technologies. IEEE Journal of Translational Engineering in Health and Medicine , (4)

- $\quad$ van Gemert-Pijnen, J. E., Nijland, N., van Limburg, M., Ossebaard, H. C., Kelders, S. M., Eysenbach, G., \& Seydel, E. R. (2011). A holistic framework to improve the uptake and impact of eHealth technologies. Journal of medical Internet research, 13(4). 